\title{
Masculinidades trans em debate: uma revisão da literatura sobre masculinidades trans no Brasil
}

\section{Debating Trans masculinities: a literature review on trans masculinities in Brazil}

\author{
Pamella Liz Nunes Pereira ${ }^{a}$ \\ (iD) https://orcid.org/0000-0002-7276-9922 \\ E-mail: pamella.lizzœgmail.com \\ Paula Gaudenzi ${ }^{\mathrm{a}}$ \\ (iD) https://orcid.org/0000-0003-4039-1088 \\ E-mail: paula.gaudenzi®gmail.com

\section{Claudia Bonan ${ }^{a}$} \\ (iD) https://orcid.org/0000-0001-8695-6828 \\ E-mail: cbonan®globo.com \\ aFiocruz/IFF. Departamento de Ensino. Rio de Janeiro, RJ, Brasil.
}

\section{Resumo}

Este trabalho analisa artigos, teses e dissertações que tratam das masculinidades trans na realidade brasileira. A busca foi realizada entre junho de 2018 e fevereiro de 2019 no Portal Regional da Biblioteca Virtual de Saúde (BVS) e no Banco de Teses e Dissertações da Capes. Para interagir mais profundamente com o corpus de análise, o material foi tratado a partir da análise de conteúdo temática. Tal análise gerou três temas principais: construção da identidade transmasculina; (in)visibilidade dos homens trans; corpo, saúde e hormonização. Identificou-se ainda uma temática residual: família e decisões reprodutivas. Em relação à problemática da identidade trans, o que parece estar em jogo é o alargamento ou a delimitação dos significantes da categoria "homem". Sobre a temática da invisibilidade, observou-se um aumento da produção acadêmica sobre o tema e uma tensão entre a passabilidade e as demandas ativismo político. Quanto ao acesso à saúde, persistem os problemas relacionados à baixa cobertura e ao despreparo das equipes de saúde para lidar com as especificidades dos homens trans. Por fim, as questões reprodutivas ainda estão sendo semeadas e lançam mais perguntas que respostas. Palavras-chave: Transexualidade; Homens; Transgeneridade.

\section{Correspondência}


Our study analyzes articles, theses and dissertations that discuss trans masculinities in Brazilian reality with a sociocultural approach. The search was conducted between June 2018 and February 2019 in two brazilian academic databases, the Portal Regional da Biblioteca Virtual de Saúde (BVS) and the Banco de Teses e Dissertações da Capes. To interact more deeply with the data, the material was approached by thematic content analysis. This analysis generated three main themes: Transmasculine identity construction; (In) visibility of Trans Men; and Body, health and hormones. A residual theme was also identified: Family and reproductive decisions. Regarding the problem of trans identity, the major conflict seems to be the widening or delimitation of the meaning of the category man. About invisibility, there was an increase of the researches about the theme, and there is a clear tension in between passing as cis man and contribute as public figures on social movements. Regarding access to health, the problems are related to the low coverage and to the failure of health teams in dealing with the specificities of trans men. Finally, reproductive questions are still being sown, casting more questions than answers.

Keywords: Transsexuality; Men; Transgender.
Na contemporaneidade, "transexualidade" e "transgeneridade" são termos que abrigam diversas experiências que têm como base comum o desacordo vivido entre o gênero desejado, sentido e/ou escolhido pelo próprio sujeito e o gênero designado socialmente no momento do nascimento. Desde a segunda metade do século XX, a definição desses termos envolve acirrados debates travados principalmente nos campos científico, médico, jurídico e do ativismo político. No contexto de profundos questionamentos e disputas sobre as origens da sexualidade humana, médicos, psicólogos, mídias de massa, sujeitos transexuais e outros atores de diversas afiliações têm proliferado discursos sobre o tema (Bento, 2006; Loyola, 2003).

Em seu livro Inventando o sexo: dos gregos a Freud, Laqueur (1994) aponta o caráter situacional e interpretativo dos sexos biológicos, nos trazendo a compreensão das classificações sexuais como construtos que operam dentro de um "campo das relações entre gênero e poder" (Rohden, 1998. p. 128). 0 autor demonstra que a concepção de sexo variou dentro do pensamento filosófico e científico em diferentes momentos históricos e explica como a noção grega de "sexo único" - segundo a qual homens e mulheres possuem uma mesma biologia que se expressa de formas diferentes de acordo com a quantidade de calor presente em cada corpo - foi substituída pela concepção binária de sexo, na qual homens e mulheres possuem biologias radicalmente diferentes, cada um com um tipo corporal específico.

De acordo com Butler (2003), os Estados modernos se organizam em torno de um sistema de gênero binário que pressupõe a heterossexualidade como condição sexual "natural" e compulsória, em que pênis, vaginas e outros caracteres corporais eleitos como sexuais determinam as preferências afetivo-sexuais e os comportamentos dos sujeitos, que são divididos entre homens e mulheres. A autora vê esse tipo de vinculação como a principal chave de inteligibilidade utilizada para interpretar os corpos humanos desde então. A transexualidade, no entanto, coloca em questão a crença no binarismo e na incomensurabilidade entre os sexos ao evidenciar que o trânsito de mulher para homem e de homem 
para mulher não apenas é possível, como cada vez mais frequente.

Para efeitos deste estudo, é importante observar que, até o início de 2018, o termo transexualismo constava na Classificação Estatística Internacional de Doenças e Problemas Relacionados com a Saúde (CID-10) como um transtorno mental que afeta a personalidade e o comportamento (OMS, 1997). Na versão mais atual do manual, o CID-11 ${ }^{8}$, não aparece mais esse termo, mas sim "incongruência de gênero" que "é caracterizada por uma marcada e persistente incongruência entre o gênero experimentado pelo indivíduo e o sexo assignado" pela Organização Mundial de Saúde (ICD-11, 2019. tradução nossa).

O termo "transexualismo" integrava também, desde sua terceira versão, o Manual Diagnóstico e Estatístico das Desordens Mentais ${ }^{9}$ - DSM-3, de 1980 (APA, 1980), subsumido no grupo maior dos "Transtornos de identidade de gênero" (Russo; Venâncio, 20o6). Na quinta versão do $\mathrm{DSM}^{11}$, de 2013, "Disforia de Gênero" passou a ser o nome do capítulo geral (APA, 2013). Como o próprio manual anuncia, essa

é uma nova classe diagnóstica no DSM-5 e reflete uma modificação na conceitualização das características definidoras do transtorno, enfatizando o fenômeno de 'incongruência de gênero' em vez da identificação transgênero per se, como era o caso no transtorno de identidade de gênero no DSM-IV ${ }^{11}$. (p. 814)

Nas várias versões desses manuais, há combinações variadas dos termos "transtorno", "disforia", "desordem" e "incongruência”, entrecruzadas com as adjetivações "sexual" ou "de gênero". Apesar das mudanças e revisões, tais formas de classificação ainda clamam por uma coerência de sexo-gênero, ancorada na (cis) heteronormatividade ${ }^{1}$ (Bonassi, 2017). O fato da experiência trans ainda estar nas páginas de manuais que classificam e quantificam doenças e transtornos indica a persistência da patologização, que cristaliza o estigma de doente para as pessoas trans.

No Brasil, as interpretações médicas sobre as performances trans seguiram o padrão internacional e as classificações do CID e do DSM. Com isso, renomearam-se as expressões de gênero não heteronormativas, que tinham nomes e definições locais, a partir dos parâmetros diagnósticos do "transexualismo".

Quanto ao processo transexualizador no Sistema Único de Saúde (SUS), o mesmo foi instituído pela Portaria $n^{\circ} 1.707 / 2008^{13}$ do Ministério da Saúde (Brasil, 2008), e ofereceu inicialmente procedimentos que contemplavam as mulheres trans. Dois anos depois, em 2010, foram inseridos procedimentos dirigidos especificamente às necessidades dos homens trans, mas quais seriam as necessidades dos homens trans? Não se pode responder a esta pergunta de forma irrefletida e com pretensões de universalizar as experiências, No entanto, vê-se que os estudos sobre masculinidades têm ganhado espaço no meio acadêmico (Pamplona, 2017), e nos perguntamos se o mesmo acontece com os estudos sobre transmasculinidades e o que está sendo produzido sobre os mesmos.

Neste artigo, propusemo-nos a fazer uma incursão crítica na literatura sobre transmasculinidades brasileiras com o objetivo de investigar sob quais perspectivas as experiências locais dos homens trans têm sido estudadas.

\section{Metodologia}

Realizou-se uma revisão bibliográfica entre junho de 2018 e fevereiro de 2019 de trabalhos acadêmicos de abordagem sociocultural sobre masculinidades trans na realidade brasileira. A busca foi realizada no Portal Regional da Biblioteca Virtual de Saúde (BVS), com o filtro "País/região como assunto" - Brasil, e no Banco de Teses e Dissertações da Capes, como detalhado na tabela abaixo.

\footnotetext{
10 termo cisgênero (cis) data da década de 1990 e foi publicizado no meio do ciberativismo trans e não binário. 0 termo nomeia os indivíduos que concordam com o sexo-gênero que lhes foi atribuído ao nascer.
} 
Tabela I - Descritores

\begin{tabular}{|c|c|c|c|c|}
\hline Descritores & Portal BVS & Selecionados & $\begin{array}{c}\text { Banco de teses e } \\
\text { dissertações da capes }\end{array}$ & Selecionados \\
\hline Transexualidade AND Homens & 39 & 2 & 34 & 12 \\
\hline Transgenero AND Homens & 15 & 3 & 18 & 2 \\
\hline Transexualismo AND Homens & 36 & 0 & 2 & I \\
\hline Transgeneridade AND Homens & 34 & 0 & 8 & I \\
\hline Transexualidade AND Masculino & 27 & । & 26 & 3 \\
\hline Transgenero AND Masculino & 23 & । & 9 & 0 \\
\hline Transexualismo AND Masculino & 25 & । & 15 & 0 \\
\hline Transgeneridade AND Masculino & 25 & 0 & 4 & 0 \\
\hline Total & 224 & 8 & 116 & 19 \\
\hline
\end{tabular}

O primeiro levantamento resultou em 340 produções acadêmicas. Foram estabelecidos como critérios de inclusão: artigos que abordassem exclusiva ou centralmente a temática das transmasculinidades; ser um estudo sobre a realidade brasileira; estar disponível integral e gratuitamente. Como critérios de exclusão estabeleceu-se: estudos com discussões restritas aos aspectos biológicos e/ ou clínicos; que abordam outras realidades que não a brasileira; que tratam das transmasculinidades em conjunto com outros temas sem dar centralidade à mesma; e as duplicações. Desse modo, foram selecionadas 26 produções acadêmicas, entre artigos, dissertações e teses.

\section{Tabela 2 - Trabalhos selecionados}

\begin{tabular}{|c|c|c|c|c|c|}
\hline Título & Autor & Ano & $\begin{array}{l}\text { Tipo de } \\
\text { publicação }\end{array}$ & Região & Área \\
\hline $\begin{array}{l}\text { Homens trans: novos matizes na } \\
\text { aquarela das masculinidades }\end{array}$ & $\begin{array}{l}\text { Almeida, } \\
\text { Guilherme }\end{array}$ & 2012 & Artigo & Sudeste & $\begin{array}{l}\text { Interdisciplinar } \\
\text { em ciências } \\
\text { humanas }\end{array}$ \\
\hline $\begin{array}{l}\text { Holofotes sobre carnes: transhomens } \\
\text { nas artes }\end{array}$ & $\begin{array}{l}\text { Costa, Iracy Rubia } \\
\text { Vaz Da }\end{array}$ & 2013 & Dissertação & Norte & Artes \\
\hline $\begin{array}{l}\text { FTM, transhomem, homem trans, } \\
\text { trans, homem: a emergência } \\
\text { de transmasculinidades no } \\
\text { Brasil contemporâneo }\end{array}$ & $\begin{array}{l}\text { Ávila, Simone } \\
\text { Nunes }\end{array}$ & 2014 & Tese & Sul & $\begin{array}{l}\text { Interdisciplinar } \\
\text { em ciências } \\
\text { humanas }\end{array}$ \\
\hline $\begin{array}{l}\text { Homens com T maiúsculo. processos } \\
\text { de identificação e construção do } \\
\text { corpo nas transmasculinidades e } \\
\text { a transversalidade da internet }\end{array}$ & $\begin{array}{l}\text { Freitas, Rafaela } \\
\text { Vasconcelos }\end{array}$ & 2014 & Dissertação & sudeste & Psicologia \\
\hline $\begin{array}{l}\text { "Somos quem podemos ser": os homens } \\
\text { (trans) brasileiros e o discurso pela } \\
\text { (des)patologização da transexualidade' }\end{array}$ & $\begin{array}{l}\text { Oliveira, Andre } \\
\text { Lucas Guerreiro }\end{array}$ & 2015 & Dissertação & Nordeste & Ciências sociais \\
\hline $\begin{array}{l}\text { Viver e esperar viver: corpo e } \\
\text { identidade na transição de gênero de } \\
\text { homens trans. }\end{array}$ & $\begin{array}{l}\text { Rego, Francisco } \\
\text { Cleiton Vieira } \\
\text { Silva do }\end{array}$ & 2015 & Dissertação & Nordeste & Antropologia \\
\hline
\end{tabular}


Tabela 2-Continuação

\section{Título \\ Transmasculinidades e o cuidado em saúde: desafios e impasses por vidas não-fascistas \\ Homens (in)visíveis - a experiência de transhomens brasileiros nas mídias virtuais \\ Gênero, corpo, saúde e direitos: experiências e narrativas de homens (trans) e homens (boys) em espaços públicos \\ Os processos de hormonização $e$ a produção do cuidado em saúde na transexualidade masculina}

João W. Nery - a trajetória de um trans homem no brasil: do escritor ao ativista

Pedagogias de gênero em narrativas sobre transmasculinidades

Transmasculinidade e os

desafios cotidianos

Presos na teoria errada" entre mulheres, "bofinhos" e homens trans

Homens trans(bordados): experiências juntas e misturadas na produção de outras masculinidades

Papai ou mamãe? uma discussão dos papéis parentais em homens trans que engravidaram

Existe uma barreira que faz com que as pessoas trans não cheguem lá: itinerários terapêuticos, necessidades e demandas de saúde de homens trans no município de Salvador-BA

"Viver dignamente": necessidades e demandas de saúde de homens trans em Salvador, Bahia, Brasil

Homens transexuais e saúde:

a efetivação do acesso à saúde de homens trans e a criação do núcleo trans unifesp Homens que engravidam: um estudo etnográfico sobre parentalidades trans e reprodução

Negociando com as normas: transexualidades masculinas, reconhecimentos e agências

\section{Autor}

Ano

Tipo de

publicação

Neves, Benjamin

Braga

2015

Dissertação

Região

Área

Amorim, Alexandre

De Souza

2016

Dissertação

Sul

Psicologia

Cordeiro, Ana

Carolina Silva

2016

Dissertação Nordeste

Antropologia

Lima, Fátima;

Cruz, Kathleen

Tereza da

2016 Artigo

Nery, João Walter;

Coelho, Maria

Thereza Ávila

Dantas; Sampaio,

Liliana Lopes Pedral

Pamplona, Renata

Silva

2017

2017

2017

2017

2017 Tese

Aquinoã Abigail

Silva, Diogo Sousa.

2017

Sousa, Diogo;

Iriart, Jorge.

2018

Cervi, Thales de

Almeida Nogueira

2018

Monteiro, Anne

Alencar

2018

Ribeiro, Daniel de

Oliveira Medeiros
2018
Tese

Artigo

Artigo

Dissertação

Sudeste

dissertação

Nordeste

Saúde coletiva

Artigo

Dissertação Sudeste

Saúde coletiva

Dissertação Nordeste

Antropologia

Interdisciplinar

em ciências

humanas

Interdisciplinar

em ciências

humanas

Educação

Educação

Interdisciplinar

em ciências

humanas

Psicologia

institucional

Psicologia

Saúde pública

Dissertação Sudeste

Ciências sociais 


\begin{tabular}{|c|c|c|c|c|c|}
\hline Título & Autor & Ano & $\begin{array}{l}\text { Tipo de } \\
\text { publicação }\end{array}$ & Região & Área \\
\hline $\begin{array}{l}\text { "Uma viagem nem tão solitária": } \\
\text { uma experiência de produção } \\
\text { de masculinidade }\end{array}$ & $\begin{array}{l}\text { Silva, Junior } \\
\text { Augusto da }\end{array}$ & 2018 & Dissertação & Sudeste & Saúde coletiva \\
\hline $\begin{array}{l}\text { Parentes" e "recursos" que fazem a } \\
\text { diferença nas relações familiares de } \\
\text { homens trans }\end{array}$ & $\begin{array}{l}\text { Rego, Francisco } \\
\text { Cleiton Vieira } \\
\text { Silva do }\end{array}$ & 2018 & Artigo & Nordeste & Sociologia \\
\hline $\begin{array}{l}\text { Uma análise sobre transmasculinidades } \\
\text { presentes numa série da mídia televisiva }\end{array}$ & $\begin{array}{l}\text { Aguiar, Thais } \\
\text { Geraldo Oliveira; } \\
\text { Quadrado, Raquel } \\
\text { Pereira }\end{array}$ & 2018 & Artigo & Sudeste & $\begin{array}{l}\text { Interdisciplinar } \\
\text { em ciências } \\
\text { humanas }\end{array}$ \\
\hline $\begin{array}{l}\text { Experiências Transmasculinas: o limiar } \\
\text { entre corpo, gênero e desejo na } \\
\text { constituição de um sentido de si }\end{array}$ & $\begin{array}{l}\text { Ribeiro, Andressa } \\
\text { De Freitas }\end{array}$ & 2018 & Tese & Nordeste & Antropologia \\
\hline $\begin{array}{l}\text { Transmasculinidade, corpo e cuidado } \\
\text { de si: análise da transexualidade no } \\
\text { Ambulatório TT da cidade de João Pessoa }\end{array}$ & $\begin{array}{l}\text { Vale, Johnatan } \\
\text { Ferreira Marques. }\end{array}$ & 2018 & tese & Nordeste & Sociologia \\
\hline
\end{tabular}

Para interagir mais profundamente com o corpus de análise e extrair um nível elevado de entendimento das mensagens contidas, o material foi tratado a partir da análise de conteúdo temática, que, de acordo com Gomes e Nascimento (2006), consiste na seguinte adaptação da técnica de análise de conteúdo: (1) leitura dos textos selecionados; (2) identificação das ideias centrais de cada estudo; (3) classificação das ideias em torno de núcleos de sentido; (4) classificação dos núcleos de sentido em eixos mais abrangentes (temas) em torno dos quais giravam as discussões dos autores e (5) redação das sínteses interpretativas de cada tema. Para a organização da interpretação do corpus, o núcleo de sentido e o tema integraram "um mesmo processo analítico, sendo o primeiro o ponto de partida para estabelecer-se o segundo" (2006, p. 903), portanto, o tema está sendo entendido como uma categoria mais ampla que pode incluir mais de um núcleo de sentido.

\section{Resultados e discussão}

A publicação mais antiga sobre transexualidade masculina nas bases pesquisadas é o artigo Homens trans: novos matizes na aquarela das masculinidades, de Guilherme Almeida (2012). Desde então, houve publicações sobre o tema em todos os anos até fevereiro de 2019, ano final das buscas feitas para esse estudo.
As áreas de estudo que concentram a maior parte das publicações selecionadas são a psicologia e a antropologia e ambas abordam fundamentalmente a dimensão da experiência dos homens trans enquanto um grupo de indivíduos em constante construção de si, de seus corpos e de seus grupos familiares. As publicações feitas em programas e revistas dos campos da educação, sociologia, saúde pública, saúde coletiva e artes tomam as experiências em conjunto com questões como direitos civis, acesso aos sistemas de saúde e educacional e representação pública da imagem dos homens trans nas mídias de massa. Foi considerada a área do local de publicação, ou seja, dos programas de pós-graduação ou das revistas científicas. Um dos trabalhos analisados foi publicado em um programa de pós-graduação em clínica médica, porém, todo o referencial teórico utilizado foi das ciências humanas.

Os principais eixos temáticos presentes nos debates sobre homens trans no Brasil, identificados a partir da análise de conteúdo temático, foram: (1) construção da identidade transmasculina, (2) (in visibilidade dos homens trans, (3) corpo, saúde e hormonização e, de maneira residual, (4) família e decisões reprodutivas. A seguir, serão apresentadas e analisadas as principais questões trazidas nos estudos acadêmicos sobre as transmasculinidades e seus processos. 


\section{Construção da identidade transmasculina}

Identificou-se nos trabalhos selecionados que a construção de um sentido de si é uma temática bastante frequente e é trazida a partir da tentativa de especificar o que constitui uma identidade de gênero. Em relação à transexualidade masculina, as explicações de como ocorre essa construção são frequentemente acompanhadas por relatos sobre experiências lésbicas anteriormente vivenciadas. Em outros termos, é comum que os homens trans apontem terem se identificado como lésbicas em alguma fase da vida.

Neste sentido, os trabalhos encontrados no corpus desta pesquisa buscam uma maneira de especificar o que supostamente seriam os homens trans e o que os constitui como uma categoria de subjetivação de sujeitos sexuados, se questionando se há ou não uma associação com a lesbianidade (Ávila, 2014; Freitas, 2014; Ribeiro, 2018a; Ribeiro, 2018b; Halberstam, 1998). O pesquisador Guilherme Almeida delineia alguns grupos de pessoas lésbicas que se identificam com a masculinidade, mas não se dizem homens, portanto, apesar de existirem muitas performances masculinas no mundo lésbico, os homens trans buscam afirmar-se de uma maneira específica, que se distingue da lesbianidade e que está ligada majoritariamente ou totalmente aos signos do gênero masculino (Almeida, 2012).

Sobre as fronteiras entre a masculinidade e o corpo designado como feminino, Simone Ávila (2014) e Benjamin Braga Neves (2015) partem do conceito de masculinidades femininas de Jack Halberstam (1998), presente na obra Female Masculinity, em que o autor demonstra através de registros históricos, filmes e literatura acadêmica, que a masculinidade foi e é também exercida por sujeitos designados como mulheres. $\mathrm{O}$ autor toma como exemplo as mulheres em cargos de chefia retratadas no cinema e na literatura, as butches (lésbicas masculinas em tradução livre) e as performances de drag kings. Evidencia-se nesse estudo que, dentro da categoria lésbica, há tantas normatizações quanto nas categorias heterossexuais, o que Halberstam (2012) nomeia "homonormatividade".

A distinção radical entre os homens trans que nunca se identificaram como lésbicas e os que já se identificaram dessa forma é o alvo principal das críticas de Halberstam (1998), que vê nesse tipo de segregação um enfraquecimento dos grupos que transgridem a heteronormatividade, com o agravante de o critério de separação ser uma reprodução da base heteronormativa em que há uma busca constante por uma essência masculina ou feminina.

É importante observar que não só corpos classificados como femininos são questionados quando assumem uma vivência vista como masculina. Diversos corpos com pênis são também constantemente questionados em suas masculinidades por não se encaixarem no modelo idealizado de masculinidade. Pedro Paulo Oliveira (2004) ressalta que o que se entende por masculinidade no Ocidente é fruto de “complexas elaborações culturais", especialmente as que ocorreram na transição das sociedades medievais para a modernidade. Tal processo envolveu uma série de transformações sociais compulsórias e violentas que tiveram sucesso por meio da força dos exércitos e da garantia do cumprimento de diversas normas repressoras, porém, tal construção sempre esteve em choque com a multiplicidade de experiências que constituem as masculinidades ao redor do mundo (Silva, 2018). Nos debates atuais, o reconhecimento da masculinidade dos homens trans, dos gays e das mulheres masculinas produziram um impacto teórico importante nos estudos sobre masculinidades, pois deslocaram do corpo masculino o poder de determinar a masculinidade. Desde os anos de 1980, diversos estudiosos propõem que a masculinidade é múltipla, porém, hierarquizada no que diz respeito às relações de poder entre os sexos e gêneros (Carrigan; Connell; Lee, 1985).

No esteio dessa discussão, Francisco do Rego (2017) identifica no debate brasileiro sobre masculinidades trans uma tendência - vista por ele como exagerada a enfatizar os comportamentos ditos femininos desempenhados pelos homens trans, o que pode reforçar a noção de que há comportamentos femininos e masculinos inatos. Este autor rejeita as análises das experiências lésbicas como relevantes para o debate sobre as transmasculinidades e radicaliza o argumento ao dizer que não considera as duas identidades como equivalentes nos níveis teórico e prático. Para ele, as experiências dos homens trans não condizem com as noções usualmente utilizadas 
para analisá-las, tais como a de "masculinidades femininas" de Jack Halberstan (1998), pois tal perspectiva se mostra insuficiente na medida em que oferece um viés etapista ao processo de transição de sexo-gênero dos homens trans.

Nos debates travados por Halberstan (1998) e Rego (2017), o que parece estar em jogo é o alargamento ou a delimitação dos significantes da categoria homem trans. Para Rego (2017), o conflito interpretativo se dá principalmente em relação ao que é chamado por Halberstam (1998) de Stone Butch, performance que é usualmente interpretada como um predecessor da identidade de homem trans. O autor busca combater essa ligação necessária entre as lesbiandades e as transmasculinidades, vendo ambas como expressões de sexo-gênero diferentes e independentes, enfatizando que lesbianidade é pensada a partir da homossexualidade, ou seja, da orientação sexual; algo que não é necessário para as transmasculinidades, que se situam no terreno da identidade sexual e não da orientação sexual.

Tal debate remonta o trabalho de Peter Fry (1982), em que são propostos dois sistemas de classificação das homossexualidades no Brasil dos anos 1970/8o, o sistema bicha/bofe e o sistema gay/gay, o que na época revelou a tensão entre categorias de desejo sexual e de performance de gênero, que no limite leva ao inevitável debate sobre os limites da total separação analítica entre gênero e sexualidade (Carvalho, 2011).

\section{(In)visibilidade dos homens trans}

Na década de 1990, as travestis foram as primeiras a reivindicarem o direito às modificações corporais e à visibilidade no Brasil. Nessa época, elas eram quase que exclusivamente retratadas a partir na categoria "grupo de risco" nas pesquisas acadêmicas, em razão da alta prevalência de soropositividade de HIV/aids e da violência direcionada a elas nos locais de trabalho. Por essas razões, as travestis fundaram na mesma década de 1990 as primeiras organizações não governamentais que tinham como missão a afirmação da importância da garantia de seu direito à vida, com foco no combate à violência policial praticada em locais de prostituição e garantia do tratamento adequado para o HIV/ aids (Carvalho, 2011). Posteriormente, a alteração do prenome no registro civil e a garantia das modificações corporais como um direito tornaramse também pautas fundamentais, pois implicam no próprio reconhecimento da existência de travestis e transexuais (Carvalho; Carrara, 2013).

De acordo com Ávila (2014), antes de 2010, os movimentos sociais de ativismo de travestis e transexuais no Brasil eram marcadamente femininos, embora já houvesse nos movimentos sociais a presença de homens trans que lutavam pelo direito aos seus corpos masculinos desde a década de 1970, como João Nery e Raicarlos Coelho (Costa, 2013; Nery; Coelho; Sampaio, 2015). Em sua tese de doutorado, a autora aponta que o registro mais antigo da presença de um homem trans em um encontro de movimentos sociais organizados na luta pelos direitos de travestis e transexuais foi de Alexandre Peixe no XII ENTLAIDS, no ano de 2005.

Ainda de acordo com Ávila, os movimentos sociais organizados que se dedicaram exclusivamente aos homens trans começaram através da iniciativa do Núcleo de Apoio a Homens Transexuais (NAHT), à época, coordenado por Andreas Maurice Boschetti. O NATH foi a gênese da criação da Associação Brasileira de Homens Trans (ABHT), que teve a sua fundação oficializada em 30 de junho de 2011 e tinha como presidente Leonardo Tenório. Ávila (2014, p. 191) ressalta que a ABHT foi a "primeira organização da sociedade civil sem fins lucrativos, que objetiva reivindicar e garantir os direitos humanos da população transmasculina no Brasil". A associação aceitava homens não cis de diversas denominações, tais como homens trans, transhomens, female to male (FTM) e transgêneros.

Outra importante célula de atuação política organizada pelos direitos dos homens trans, o Instituto Brasileiro de Transmasculinidades (IBRAT), foi fundada em julho de 2013 na capital paraibana João Pessoa. No momento de sua fundação, o instituto era coordenado centralmente por Luciano Palhano e tinha três coordenadores regionais: Xande Peixe (SP), Raicarlos Coelho (PA), e Sillvyo Nóbrega (CE) (Ávila, 2014).

O IBRAT incluía em sua formação transhomens, instituições e pessoas parceiras, acadêmicos, ativistas militantes, estudantes e profissionais voluntários. De acordo com Benjamin Braga 
Neves (2015) o IBRAT é "uma rede nacional de homens trans ativistas que atua nos eixos da formação política, estudos e pesquisas sobre transmasculinidades e controle social” (2015, p. 44).

A criação de associações, institutos e núcleos específicos e o aumento da presença de homens trans nos encontros regionais e nacionais de travestis e transexuais marcaram o início do movimento social organizado dos homens trans.

Observa-se que em relação às mulheres trans e travestis, a atuação política organizada dos homens trans é relativamente nova. Tal fato ainda carece de mais análises que ajudem a compreender os fatores associados à menor representação pública dos interesses políticos dos homens trans até o momento. Como reação a esse panorama, há uma proliferação da literatura acadêmica que denuncia a invisibilidade dos homens trans em pesquisas e políticas públicas, além da inclusão das pautas relativas a estes nos trabalhos sobre mulheres trans e transexualidades.

Guilherme Almeida (2012), Simone Ávila (2014), Rafaela Freitas (2014) e Alexandre Amorim (2016) localizam a emergência do interesse público e acadêmico pelos homens trans no Brasil a partir de 2010, ano em que o Conselho Federal de Medicina (CFM) permitiu que fossem incluídas as adequações masculinizantes no processo transexualizador. Os autores ressaltam ainda a importância da internet nesse processo de atuação pública dos homens trans que, através de blogs e canais de vídeo, começaram a retratar seus cotidianos e a apresentar as suas experiências.

Apesar da importância de homens trans que se tornaram figuras públicas, alguns autores levantam a suspeita de que muitos homens trans, principalmente os de idade mais elevada (Ávila, 2014), não buscam o reconhecimento social como pessoa trans no cotidiano. Para Almeida (2012), no caso masculino, a possibilidade de não precisar tornar pública a identidade de gênero trans é algo que pode ser associado à rápida capacidade de alguns homens trans de se tornarem indiferenciáveis dos homens cis no cotidiano, o que se costuma dar o nome de "passabilidade" (Pontes; Silva, 2017).

A autora Ana Carolina Cordeiro (2016) relata dificuldades de se localizar e/ou identificar os homens trans em espaços públicos, algo dito também em outros trabalhos (Almeida, 2012; Ávila, 2014; Freitas, 2014). A autora não só analisa a atuação social de homens trans - ou boys, outra nomenclatura encontrada pela autora no campo - em espaços públicos, como também constrói o universo de sua pesquisa privilegiando a diversidade dos sujeitos no que diz respeito à classe social, raça, autoidentificação masculina e identidade sexual.

Em seu trabalho, a nomenclatura "trans" aparece como mais usual entre os entrevistados de classe média, enquanto a nomenclatura "boys" é a mais utilizada pelos entrevistados pertencentes às classes populares, que muitas vezes não podem acessar as tecnologias necessárias para obter passabilidade como pessoa cisgênero.

Ao ler os trabalhos, podemos observar que a utilização de uma ou de outra forma de autoidentificação ocorre de maneira estratégica, ficando a cargo dos indivíduos se apresentarem da forma como pensam que serão mais bem compreendidos em cada contexto. Ademais, segundo Mário Carvalho (2018) a autoidentificação está longe se ser determinada somente por algum desejo individual. A compreensão do sexo-gênero como algo mais fixo ou mais fluido, em geral vem acompanhada por discursos marcados pela geração e classe social de quem os profere e se modificam ao longo do tempo.

\section{Corpo, saúde e hormonização}

As principais questões de saúde abordadas nos trabalhos sobre homens trans giram em torno da busca por modificações corporais e das dificuldades encontradas por eles ao acessar os serviços de saúde. Segundo Diogo Sousa e Jorge Iriart (2018) e Thales Cervi (2018), os obstáculos encontrados pelos homens trans nestes espaços é resultado, sobretudo, da transfobia, que consiste em práticas patologizantes, punitivas e violentas contra os sujeitos que se constituem a partir de outro referencial que não o da cisheteronormatividade (Sousa; Iriart, 2018).

Essa situação não tem sido encarada com passividade e importantes passos foram dados nos 
últimos anos em relação à ampliação do atendimento de saúde para homens trans. De acordo com Neves (2015), as transexualidades têm ganhado legitimidade no campo da saúde pública por meio das resoluções do Conselho Federal de Medicina (CFM), que regulamentaram as cirurgias de transgenitalização; da atuação política dos movimentos LGBTQI+ (Lésbicas, Gays, Bissexuais, Travestis,Transexuais, Queer, Intersexos e outras categorias dissidentes de sexo gênero) $^{2}$ na luta por direitos; do empenho de grupos de profissionais e técnicos da assistência em saúde; das contribuições acadêmicas dos campos da saúde coletiva, das ciências sociais e do direito (2015. p. 47).

Essas e outras iniciativas são profundamente atreladas à Política Nacional de Saúde LGBT (Lésbicas, Gays, Bissexuais, Travestis e Transexuais), que representa um importante marco em relação aos cuidados em saúde de pessoas trans (Neves, 2015). Uma dessas iniciativas é analisada por Cervi (2018) a partir da experiência do Ambulatório do Núcleo de Estudos, Pesquisa, Extensão e Assistência à Pessoa Trans Prof. Roberto Farina ${ }^{3}$, que funciona nas dependências da Universidade Federal de São Paulo (UNIFESP) como um núcleo autônomo que conta com grande participação do público estudantil. Além do atendimento ambulatorial, o núcleo oferta cursos e oficinas sobre as questões trans.

Sobre a hormonização com testosterona, Rego (2015) situa duas interpretações frequentes entre seus entrevistados: a saudável e a arriscada. A primeira corresponde ao uso sob orientação médica, com ajuste das dosagens para cada corpo, de forma que os efeitos desejados sejam mais garantidos; a segunda forma consiste na obtenção ilegal, geralmente em academias de musculação e/ ou pela internet, com o ajuste das doses orientado por tutoriais de grupos virtuais exclusivos para homens trans usuários de testosterona.

Como consequência das barreiras de acesso aos serviços de saúde a esta população - seja pela dificuldade de chegar ao serviço seja devido a práticas violentas vividas no cotidiano dos mesmos - a gestão dos hormônios se dá muitas vezes fora da esfera médica e se configura de inúmeras maneiras.

Fátima Lima e Kathleen Cruz (2016) pontuam que há uma forte relação entre as dificuldades de acesso aos hormônios nos serviços de saúde e nas farmácias e os processos de automedicação entre os transexuais, que em sua maioria começam a usar os hormônios sem acompanhamento médico.

Esta população encontra-se em uma situação delicada neste momento, pois, além dos riscos oriundos dos efeitos colaterais das medicações mal administradas, o uso de hormônios só produz os efeitos desejados quando ingeridos continuamente e na dosagem adequada.

Em todos os trabalhos analisados, a hormonização com testosterona é a principal via de performar a masculinidade para a maioria dos entrevistados. Neves (2015) abre um dos capítulos de sua dissertação com o relato de seu principal interlocutor, Jackson Tyller, em que o mesmo descreve a sua relação com a testosterona:

Sim, sempre digo que a testosterona é o passaporte da felicidade. No meu ponto de vista, conhecer o que a testosterona pode proporcionar pra mim, foi como se eu tivesse ganhado uma passagem pra felicidade, para o fim dos medos, para a liberdade de andar na rua sem medo de alguém me constranger... Um fato importante, a testosterona não mudou só meu corpo e meu rosto, ela mudou meu coração. De um coração triste para um coração feliz, com vontade de viver e não de morrer. (p. 58)

Nesse trecho, vê-se que há uma aposta na testosterona como solução para os males sofridos, evidenciando os efeitos no corpo deste hormônio, além do caráter simbólico da pílula da masculinidade. Seus efeitos adquirem um status quase que sacralizado, quando a testosterona é associada com a motivação para viver do entrevistado.

Também no trabalho de André Oliveira (2015), há falas semelhantes às de Tyller, tais como "deus salve a testosterona" e "o hormônio é o melhor amigo da

2 A sigla utilizada pelos movimentos sociais que lutam contra as normas cis e heteronormativa vem sendo adequada desde a década de 1990 com o objetivo de incluir o máximo de grupos dissidentes em relação ao sexo e ao gênero na luta por direitos civis. As modificações levam em consideração as transformações das relações de sexo e gênero relacionadas ao ativismo político.

3 Roberto Farina foi o primeiro cirurgião brasileiro a realizar, em 1971, na cidade de São Paulo, uma cirurgia de redesignação sexual. 
pessoa trans" (2015, p. 96). A partir desse tipo de relato, fica explícita a profunda importância dos hormônios para a experiência trans. Lima e Cruz (2016) afirmam que os hormônios são fundamentais para compreender a transexualidade, visto que "a história da construção dos corpos transexuais durante os séculos XX e XXI só é possível de ser discutida levando em consideração a relação e a importância do uso de hormônios nas construções corporais e nos processos subjetivos" (2016. p. 177). É também o que apontam Benjamin Braga Neves (2015) e Luiz Fernando Uchôa (2017), que colocam em evidência o uso de hormônios como algo fortemente vinculado à experiência de muitos transexuais e veem o uso da testosterona como central nos processos de construção dos homens trans como sujeitos.

Tal centralidade da testosterona na experiência de "ser homem" é resultado da vivência de insígnias masculinas que estão muito além da materialidade corpórea. Não são raros relatos sobre efeitos que são sentidos logo nas primeiras doses para além de mudanças físicas. Aumento dos pelos, modificações no tom de voz e modificação da estrutura corporal são acompanhados de um suposto incremento da racionalidade, da resistência ao cansaço e da agressividade (Oliveira, 2015).

Uma vez que ter um "pênis funcional" não é uma possibilidade para os homens trans, pode-se supor que a aposta nos caracteres performáticos masculinos ganha relevância. Como ser um homem sem pênis? Sendo agressivo, racional, tendo um corpo resistente e forte. Na era da cultura somática, em que se acredita que nossa interioridade é conformada de acordo com a organização de nossos substratos biológicos (Costa, 2004), não é difícil de entender a importância da testosterona na vida destes sujeitos.

Ademais, a hormonização parece ter prioridade quando comparada com as cirurgias, visto que algumas das intervenções precisam ser facilitadas pelos efeitos dos hormônios. A título de exemplo, pode-se citar a cirurgia para a fabricação peniana chamada metoidoplastia, que é feita após o crescimento do clitóris estimulado pela ação da testosterona. A vagina virilizada fica com um aspecto peniano e com a sensibilidade local preservada, mas ainda não há como fazer cirurgicamente um pênis tal qual o pênis dos corpos biologicamente designados como homens em que o desejo sexual promove a ereção.

No cruzamento entre a submissão e a subversão dos corpos, os hormônios emergiram com uma possibilidade de modular-se internamente ao invés de disciplinar-se por meio de ferramentas externas, seguindo a lógica do biopoder, descrito por Foucault (2003). Nas primeiras décadas do século XX, os hormônios sexuais passaram a ser compreendidos como "mensageiros químicos" da feminilidade e da masculinidade e foram centrais no desenvolvimento de uma nova interpretação da fisiologia dos corpos (Oudshoorn, 1994). Com essas novas maneiras de intervir no corpo, os caracteres corporais ditos masculinos e femininos, antes pensados como intransponíveis corporalmente, poderiam ser desde então adquiridos através do uso dos hormônios. Neste imbróglio, foram se construindo as atuais práticas corporais dos trans ao redor do mundo (Preciado, 2008).

\section{Família e decisões reprodutivas}

Os estudos sobre aspectos familiares e reprodutivos de homens trans são os mais recentemente publicados e ainda são pouco frequentes. As questões até então trabalhadas dizem respeito ao rompimento com as famílias e às questões reprodutivas.

No estudo de Anne Monteiro (2018), grande parte dos entrevistados relataram a situação de rompimento com o seio familiar em razão da usual tensão relacionada ao trânsito de gênero, pois em muitos casos, esses sujeitos não fazem "sentido dentro da lógica de parentesco que exige cada qual no seu lugar, exercendo uma função preestabelecida” (2018. p. 94).

Para Rego (2018), apesar da transição de corpo e de gênero ser vista como uma zona de tensão para as famílias, ela não seria a única responsável pelo rompimento dos laços familiares-afetivos. $\mathrm{O}$ autor coloca em evidência o fato de que, frequentemente, tensões familiares e desentendimentos se dão por variadas questões que operam em conjunto com a problemática sexo-gênero, uma vez que as relações familiares são também um instrumento de acumulação de capital (financeiro, cultural etc.). Além disso, o autor pontua que os conflitos e rupturas são constitutivos das relações familiares que não operam na lógica ideal da família nuclear no cotidiano. 
Questões financeiras, de gênero, e debates sobre a função "adequada" de cada um de seus membros, reorganizam constantemente o grupo familiar.

Sobre as questões reprodutivas, o que chama atenção é a interação complexa entre o não reconhecimento de si como homem durante o período gestacional e a capacidade de gestar (Monteiro, 2018; Pederzoli, 2017). No entanto, os homens trans dos estudos analisados que engravidaram parecem estar construindo novas formas de experimentar o evento da gravidez no que diz respeito à vivência de seus gêneros, pois não reconhecem as suas gestações como pertencentes à maternidade e à condição feminina. O período gestacional é vivido como algo passageiro, e eles não se sentem condenados a abandonar o processo de masculinização depois de terem filhos (Monteiro, 2018; Pederzoli, 2017). Monteiro (2018) explora a metáfora do cavalo marinho, por ser uma espécie em que o macho carrega o fruto da fecundação e nem por isso deixa de ser macho, essa metáfora está também presente em canais de vídeo e grupos virtuais de homens trans que narram suas experiências.

Pode-se supor que as experiências trans estejam trazendo mudanças no terreno da relação entre os sexos/gêneros a partir dos papeis sociais ligados à parentalidade. Tanto Anne Monteiro (2018) quanto Aquinoã Pederzoli (2017) relatam que, para muitos homens trans entrevistados, a maternidade e a paternidade têm funções semelhantes, porém, eles foram os responsáveis pela gestação. Nesse sentido, mãe e pai tornam-se nomenclaturas cujas definições são consideravelmente modificadas no caso das transparentalidades.

\section{Considerações finais}

A imersão nos trabalhos sobre masculinidades trans na realidade brasileira ofereceu um panorama geral dos núcleos de sentido e dos grandes temas em que têm sido inseridas as histórias dos homens trans.

No eixo temático das (in)visibilidades, observou-se que a administração da testosterona pode conferir aos corpos que não pareciam masculinos as características tradicionalmente associadas à masculinidade cisnormativa, o que tem diversas implicações subjetivas e práticas. Uma delas é que uma vez que mostrar o corpo trans pode incorrer em experiências violentas, ter um corpo padronizado torna-se em várias situações uma necessidade. Por esta razão, muitas pessoas trans buscam se proteger dos efeitos deletérios da transfobia através da transformação de seus corpos (Almeida, 2012; Carvalho, 2018).

Por outro lado, fazer aparecer o corpo trans e dizer-se trans publicamente é fruto de um processo sociopolítico que disputa a validação das identidades de gênero que não são cis-heteronormativas.

Nas discussões sobre a construção de si, individual e coletiva, dos homens trans, o que parece estar em jogo é o alargamento ou a delimitação dos significantes da categoria homem e a tensão gerada pela inclusão de corpos anteriormente nomeados como femininos nessa categoria. Conforme apontamos, as experiências prévias como mulheres lésbicas, ou como mulheres cis e hétero, devem ser consideradas quando exploramos as experiências das masculinidades trans. Além de estas vivências serem recorrentes nos relatos utilizados nos trabalhos levantados, é preciso considerar os limites do corpo para efeitos de reconhecimento das identidades de gênero em culturas nas quais a cisheteronormatividade é hegemônica, principalmente quando pensamos em corpos desprovidos de acesso a tecnologias tais como hormônios e cirurgias.

As vivências que se assemelham ao modelo apresentado por Halberstam (1998) podem significar múltiplas identidades, mas todas têm em comum o reconhecimento social da transgressão que cometeram ao adotar traços masculinos tendo corpos pensados como ilegítimos para esta prática de gênero.

Outro ponto importante são as questões estratégicas para a obtenção de direitos civis. É notório que incluir-se na categoria trans é para muitos sujeitos uma maneira de reconhecimento "oficial” de suas experiências de vida, uma vez que as identidades coletivas frequentemente se convertem em instrumentos da burocracia estatal (Carvalho, 2018). Tal inclusão é importante para uma organização política desses sujeitos na qual um termo que prioriza as proximidades, ao invés das distinções entre eles, possibilita a luta comum por suas existências. No entanto, é imperioso apontar que assumir a identidade coletiva "homem trans" abriga uma infinidade de expressões de gênero masculinas.

Sobre o acesso à saúde, ainda que as iniciativas citadas sejam de grande valia, persistem os 
problemas relacionados à baixa cobertura e despreparo das equipes de saúde para lidar com as especificidades dos homens trans, que por não conseguirem acessar o serviço de saúde de maneira digna, distanciam-se do atendimento.

Em muitos casos, essas dificuldades contribuem para ingestão arriscada de testosterona sem acompanhamento qualificado (Sousa; Iriart, 2018; Lima; Cruz, 2016) e, mesmo que os hormônios estejam longe de atender de maneira integral as necessidades de saúde dos transexuais, o seu uso figura como uma prática corporal de muita relevância para performances transmasculinas, o que torna a reflexão sobre os hormônios fundamental para pensar os cuidados em saúde para essa população.

Junto do uso da testosterona, as cirurgias penianas também compõem o debate sobre construção corporal e os seus "limites". Nos trabalhos analisados, os homens trans relatam outras vias acessíveis de masculinização, deixando de lado a reprodução obsessiva do pênis (Almeida, 2012; Ávila, 2014).

As questões reprodutivas ainda estão sendo semeadas, e mais lançam perguntas que possibilitam sínteses, por este motivo, foram pouco trabalhadas neste artigo. De todo modo, percebe-se que os trabalhos pioneiros estão ancorados nas discussões sobre os papéis parentais, a gestação e a família como recurso e como zona de tensão.

\section{Referências}

AGUIAR, T. G. O.; QUADRADO, R. P. Uma análise sobre transmasculinidades presentes numa série da mídia televisiva. Revista Latino-Americana de Estudos em Cultura e Sociedade, Foz do Iguaçu, v. 4, n. especial, p. 1-9, 2018. DOI: 10.23899/ relacult.v4io. 847

ALMEIDA, G. Homens trans: novos matizes na aquarela das masculinidades? Revista Estudos Feministas, Florianópolis, v. 20, n. 2, p. 513-23, 2012. DOI: 10.1590/So104-026X2012000200012

AMORIM, A. S. Homens (in)visíveis: experiência de transhomens brasileiros nas mídias virtuais. 2016. Dissertação (Mestrado em Psicologia) Universidade Federal de Santa Catarina, Florianópolis, 2016.
APA - AMERICAN PSYCHIATRIC ASSOCIATION.

Diagnostic and statistical manual of mental disorders. 3. ed. Arlington: 1980.

APA - AMERICAN PSYCHIATRIC ASSOCIATION. Diagnostic and statistical manual of mental disorders. 5. ed. Arlington: 2013.

ÁVILA, S. FTM, transhomem, homem trans, trans, homem: a emergência de transmasculinidades no Brasil contemporâneo. 2014. Tese (Doutorado em Ciências Humanas) - Universidade Federal de Santa Catarina, Florianópolis, 2014.

BENTO, B. A reinvenção do corpo: sexualidade e gênero na experiência transexual. Rio de Janeiro: Garamond, 2006.

BONASSI, B. C. Cisnorma: acordos societários sobre o sexo binário e cisgênero. 2017. Dissertação (Mestrado em Psicologia) - Universidade Federal de Santa Catarina, Florianópolis, 2017.

BRASIL. Portaria 1.707, de 18 de agosto de 2008. Institui, no âmbito do SUS, o Processo Transexualizador, a ser implantado nas unidades federadas, respeitadas as competências das três esferas de gestão. Diário Oficial da União: Brasília, DF, 18 ago. 2008.

BUTLER, J. Problema de Gênero. Rio de Janeiro: Civilização Brasileira, 2003.

CARRIGAN, T.; CONNELL, R.; LEE, J. Toward a new sociology of masculinity. Theory and Society, Berlin, v. 14, n. 5, p. 551-604, 1985. DOI: 10.1007/BFoo160017

CARVALHO, M. F. L. Que mulher é essa? Identidade, política e saúde no movimento de travestis e transexuais. 2011. Dissertação (Mestrado em Saúde Coletiva) - Universidade do Estado do Rio de Janeiro, Rio de Janeiro, 2011.

CARVALHO, M. F. L. "Travesti”, "mulher transexual", "homem trans" e "não binário": interseccionalidades de classe e geração na produção de identidades políticas. Cadernos Pagu, Campinas, n. 52, e185211, 2018. DOI: $10.1590 / 1809444920100520011$

CARVALHO, M. F. L.; CARRARA, S. Em direção a um futuro trans? Contribuição para a história 
do movimento de travestis e transexuais no Brasil. Sexualidad, Salud y Sociedade, Rio de Janeiro, v. 14, p. 319-35, 2013. DOI: 10.1590/S198464872013000200015

CERVI, T. A. N. Homens transexuais e saúde: a efetivação do acesso à saúde de homens trans e a criação do núcleo trans. 2018. Dissertação (Mestrado em Ciências) - Universidade Federal de São Paulo, São Paulo, 2018.

CORDEIRO, A. C. S. Gênero, corpo, saúde e direitos: experiências e narrativas de homens (trans) e homens (boys) em espaços públicos. 2016. Dissertação (Mestrado em Antropologia) Universidade Federal de Pernambuco, Recife, 2016. COSTA, I. R. V. Holofotes sobre carnes: transhomens nas artes. 2013. Dissertação (Mestrado em Artes) - Universidade Federal do Pará, Belém, 2013.

COSTA, J. F. O vestígio e a aura: corpo e consumismo na moral do espetáculo. Rio de Janeiro: Garamond, 2004.

FOUCAULT, M. História da sexualidade I: a vontade de saber. 15. ed. Rio de Janeiro: Graal, 2003.

FREITAS, R. V. Homens com T maiúsculo: processos de identificação e construção do corpo nas transmasculinidades e a transversalidade da internet. 2014. Dissertação (Mestrado em Psicologia) - Universidade Federal de Minas Gerais, Belo Horizonte, 2014.

FRY, P. Da hierarquia à igualdade: a construção histórica da homossexualidade no Brasil. In: Para inglês ver: identidade e política na cultura brasileira. Rio de Janeiro: Zahar, 1982. p. 87-115.

GOMES, R.; NASCIMENTO, E. F. A produção do conhecimento da saúde pública sobre a relação homem-saúde: uma revisão bibliográfica. Cadernos de Saúde Pública, Rio de Janeiro, v. 22, n. 5, p. 901911, 2006. DOI: 10.1590/So102-311X2006000500003

HALBERSTAM, J. Female masculinity. Durham: Duke University Press, 1998.

HALBERSTAM, J. Global female masculinities. Sexualities, Thousand Oaks, v. 15, n. 3-4, p. 336-54, 2012. DOI: 10.1177/1363460712436480
ICD-11: International Classification of Diseases 11th Revision. World Health Organization, Geneva, 2019. Disponível em: https://icd.who.int. Acesso em: 30 ago. 2019.

LAQUEUR, T. Making sex: body and gender from the Greeks to Freud. Cambridge: Harvard University Press, 1994.

LIMA, F.; CRUZ, K. T. Os processos de hormonização e a produção do cuidado em saúde na transexualidade masculina. Sexualidad, Salud y Sociedade, Rio de Janeiro, n. 23, p. 162-86, 2016. DOI: 10.1590/1984-6487.sess.2016.23.07.a

LOYOLA, M. A. Sexualidade e medicina: a revolução do século XX. Cadernos de Saúde Pública, Rio de Janeiro, v. 19, n. 4, p. 875-884, 2003. DOI: 10.1590/So102-311X2003000400002

MONTEIRO, A. A. Homens que engravidam: um estudo etnográfico sobre parentalidades trans e reprodução. 2018. Dissertação (Mestrado em Antropologia) - Universidade Federal da Bahia, Salvador, 2018.

NERY, J. W.; COELHO, M. T. Á. D.; SAMPAIO, L. L. P. João W. Nery - a trajetória de um trans homem no Brasil: do escritor ao ativista. Periódicus, Salvador, v. 1, n. 4, p. 169-178, 2015.

NEVES, B. B. Transmasculinidades e o cuidado em saúde: desafios e impasses por vidas nãofascistas. 2015. Dissertação (Mestrado em Clínica Médica) - Universidade Federal do Rio de Janeiro, Rio de Janeiro, 2015.

OLIVEIRA, A. L. G. "Somos quem podemos ser": os homens (trans) brasileiros e o discurso pela (des) patologização da transexualidade. 2015. Dissertação (Mestrado em Ciências Sociais) - Universidade Federal do Rio Grande do Norte, Natal, 2015.

OLIVEIRA, P. P. A construção social da masculinidade. Belo Horizonte: Editora UFMG; Rio de Janeiro: IUPERJ, 2004.

OMS - ORGANIZAÇÃO MUNDIAL DA SAÚDE. CID-1o: Classificação Estatística Internacional de Doenças e Problemas Relacionados à Saúde. 10. ed. São Paulo: EdUSP, 1997. v. 1. 
OUDSHOORN, N. Beyond the natural body:

an archeology of sex hormones. Londres:

Routledge, 1994.

PAMPLONA, R. S. Pedagogias de gênero em narrativas sobre transmasculinidades. 2017. Dissertação (Doutorado em Educação) Universidade Federal de São Carlos, São Carlos, 2017.

\section{PEDERZOLI, A. A. Papai ou mamãe? Uma} discussão dos papéis parentais em homens trans que engravidaram. 2017. Tese (Mestrado em Psicologia) - Universidade de São Paulo, São Paulo, 2017.

PEDRINI, M. D. Homens trans(bordados): experiências juntas e misturadas na produção de outras masculinidades. 2017. Dissertação (Mestrado em Psicologia Institucional) - Universidade Federal do Espírito Santo, Vitória, 2017.

PONTES, J. C.; SILVA, C. G. Cisnormatividade e passabilidade: deslocamentos e diferenças nas narrativas de pessoas trans. Periódicus, Salvador, v. 1, n. 8, p. 396-317. 2017.

PRECIADO, P. Testo Yonqui. Madri: Espasa, 2008.

REGO, F. C. V. S. Viver e esperar viver: corpo e identidade na transição de gênero de homens trans. 2015. Dissertação (Mestrado em Antropologia Social) - Universidade Federal do Rio Grande do Norte, Natal, 2015.

REGO, F. C. V. S. "Presos na teoria errada” entre mulheres "bofinhos" e homens trans. Revista Bagoas, Natal, v. 11, n. 16, p. 233-267, 2017.

REGO, F. C. V. S. "Parentes" e "Recursos" que fazem a diferença nas relações familiares de homens trans. Inter-Legere, Natal, v. 1, n. 21, p. 63-68, 2018.

RIBEIRO, A. F. Experiências transmasculinas: o limiar entre corpo, gênero e desejo na constituição de um sentido de si. 2018. Tese (Doutorado em Ciências Sociais) - Universidade Federal da Bahia, Salvador, 2018a.

RIBEIRO, D. O. M. Negociando com as normas: transexualidades masculinas, reconhecimentos e agências. 2018. Dissertação (Mestrado em
Ciências Sociais) - Universidade Federal de Juiz de Fora, Juiz de Fora, 2018b.

ROHDEN, F. O corpo fazendo a diferença. Mana, Rio de Janeiro, v. 4, n. 2, p. 127-141, 1998. DOI: 10.1590/So104-93131998000200007

RUSSO, J.; VENÂNCIO, A. T. A. Classificando as pessoas e suas perturbações: a "revolução terminológica” do DSM III. Revista Latinoamericana de Psicopatologia Fundamental, São Paulo, v. 9, n. 3, p. 46o-483, 2006. DOI: $10.1590 / 1415-47142006003007$

SILVA, D. S. Existe uma barreira que faz com que as pessoas trans não cheguem lá: itinerários terapêuticos, necessidades e demandas de saúde de homens trans no município de Salvador-BA. 2017. Dissertação (Mestrado em Saúde Comunitária) - Universidade Federal da Bahia, Salvador, 2017.

SILVA, J. A. Uma viagem nem tão solitária: uma experiência de produção de masculinidade. 2018. Dissertação (Mestrado em Saúde Coletiva) Universidade do Estado do Rio de Janeiro, Rio de Janeiro, 2018.

SOUSA, D.; IRIART, J. "Viver dignamente": necessidades e demandas de saúde de homens trans em Salvador, Bahia, Brasil. Cadernos de Saúde Pública, Rio de Janeiro, v. 34, n. 10, p. 1-11, 2018. DOI: 10.1590/0102-311х00036318

UCHÔA, L. F. Transmasculinidade e os desafios cotidianos. Revista Educação, Guarulhos, v. 12, n. 1, p. 47-59, 2017.

VALE, J. F. M. Transmasculinidade, corpo e cuidado de si: análise da transexualidade no Ambulatório TT da cidade de João Pessoa - PB. 2018. Tese (Doutorado em Sociologia) - Universidade Federal da Paraíba, João Pessoa, 2018.

\section{Contribuição dos autores}

Todas as autoras colaboraram intelectualmente com a organização, análise dos dados, redação do manuscrito e aprovação da versão final deste trabalho.

Recebido: $27 / 02 / 2020$ Aprovado: $26 / 11 / 2020$ 